\title{
Electrochemically controlled reconstitution of immobilized ferritins for
}

\section{bioelectronic applications}

Jae-Woo Kim ${ }^{\mathrm{a}, *}$, Sang H. Choi ${ }^{b}$, Peter T. Lillehei ${ }^{b}$, Sang-Hyon Chu ${ }^{a}$, Glen C. $\operatorname{King}^{b}$, Gerald D. Watt ${ }^{c}$

${ }^{a}$ National Institute of Aerospace, Hampton, VA 23666, USA. ${ }^{b}$ Advanced Materials and Processing Branch, NASA Langley Research Center, Hampton, VA 23681, USA. ${ }^{c}$ Department of Chemistry and Biochemistry, Brigham Young University, Provo, UT 84602, USA.

* Corresponding Author. Tel: 1-757-864-1383; fax: 1-757-864-8312; E-mail:

fn.j.kim@larc.nasa.gov (J.-W. Kim)

\begin{abstract}
Site-specific reconstituted nanoparticles were fabricated via electrochemicallycontrolled biomineralization through the immobilization of biomolecules. The work reported herein includes the immobilization of ferritin with various surface modifications, the electrochemical biomineralization of ferritins with different inorganic cores, and the electrocatalytic reduction of oxygen on the reconstituted Pt-cored ferritins. Protein immobilization on the substrate is achieved by anchoring ferritins with dithiobis-Nsuccinimidyl propionate (DTSP). A reconstitution process of site-specific electrochemical biomineralization with a protein cage loads ferritins with different core materials. The ferritin acts as a nano-scale template, a biocompatible cage, and a separator between the nanoparticles. This first demonstration of electrochemically controlled site-specific
\end{abstract}


reconstitution of biomolecules provides a new tool for biomineralization and opens the way to produce the bio-templated nanoparticles by electrochemical control. The nanosized platinum-cored ferritins on gold displayed good catalytic activity for the electrochemical reduction of oxygen, which is applicable to biofuel cell applications. This results in a smaller catalyst loading on the electrodes for fuel cells or other bioelectronic devices.

Keywords: Ferritin, immobilization, reconstitution, QCM, electrocatalyst

\section{Introduction}

The immobilization of biomolecules on electrode surfaces is of great importance and interest in biosensor [1,2] and bioelectronic [3,4] applications. To develop the electrodes for the bioelectronic applications, system miniaturization and compact integration are equally important. Various inorganic molecules appear to be good candidates as energy storage and generation materials. If they are easily incorporated into biological molecules by employing bioinorganic chemistry techniques, a basic power unit can be formed on a small scale.

The ferritin used in this work is a natural iron storage protein that presents a high degree of structural similarity across a wide range of biological species [5]. The ferritin molecule is composed of 24 organic subunits that form a segmented hollow protein shell with an outer diameter of $12 \mathrm{~nm}$ and an inner diameter of $8 \mathrm{~nm}$. The mineral core of naturally existing ferritins is composed of an antiferromagnetic iron oxide (ferrihydrite) within its hollow and spherical protein interior. The assembled structure of ferritin is remarkably stable and robust, and able to withstand biologically extreme high temperatures 
(up to $70{ }^{\circ} \mathrm{C}$ ) and wide $\mathrm{pH}$ variations $(2.0 \sim 10.0)$ [6]. Ferritin protein has hydrophobic and hydrophilic molecular channels through the protein shell, which enables the removal of the inorganic phase in vitro by reductive dissolution. The reconstitution of ferrihydrite cores into a ferritin protein cage proceeds through remineralization of apoferritin, which has a protein shell without a core, by $\mathrm{Fe}^{2+}$ oxidation, usually by $\mathrm{O}_{2}$. A synthesis of ferrimagnetic ferritin $\left(\gamma-\mathrm{Fe}_{2} \mathrm{O}_{3}\right)$ was achieved by a chemical remineralization procedure $[7,8]$ with the assistance of $\mathrm{H}_{2} \mathrm{O}_{2}$ oxidant in 3-[(1,1-dimethyl-2-hydroxyethyl)amino]-2-hydroxypropanesulfonic acid(AMPSO) buffer $(\mathrm{pH} 8.5)$ at $65{ }^{\circ} \mathrm{C}$ under $\mathrm{N}_{2}$ gas. Biomineralization of other metals (i.e., Co [9,11], Mn [12-14], Ni [15], and Pd [16]), semiconductors (CdS) [17], and metal-oxo-anions composites [18] into the ferritin cavity has also been reported. Wong et al. demonstrated the magnetic transition from superparamagnetic to ferromagnetic CoPt cored ferritin [19-20]. Tetrachloroplatinate anion was moved to the ferritin core and fabricated to Pt nanoparticles by chemical reduction. The electrochemical behavior of the physically-adsorbed ferritin molecules on indium-tin oxide (ITO) glass was studied via cyclic voltammetry $[21,22]$. Zapien et al. showed that the ferritin was well adsorbed onto the ITO substrate from solution at a controlled electrode potential and could be electrochemically induced to release the iron core without the need for a reducing agent.

Ferritin arrays have been produced in many ways to obtain high-density ferritin layers. These methods include physical adsorption [23], Langmuir-Blodgett deposition [2426], mechanical scratching [27], protein crystallization [28], and electrostatic interaction between ferritin and the terminal functional groups of the self assembled monolayers [29]. In the present work, an electrochemically-controlled, site-specific biomineralization was demonstrated through the immobilization of biomolecules on a substrate to produce bio- 
templated nanoparticles. The electrode surface was modified by a molecular anchor to ensure a stable adhesion of ferritin molecules and the core was reconstituted with another metal by electrochemical methods. We used electrochemical biomineralization for the direct reconstitution of immobilized ferritins on a Au electrode. We also demonstrated the electrocatalytic behavior of Pt-reconstituted ferritin electrodes for electro-reduction of oxygen.

\section{Experimental}

\subsection{Ferritin Immobilization}

Immobilization of ferritin on the Au electrode is achieved through two different procedures. One approach is to modify the ferritin shell to have a terminal thiol group via reaction with thiol-containing organic molecules. Another approach is the modification of the $\mathrm{Au}$ electrode with thiol-derivatized molecules such as DTSP and then attaching the ferritin molecules onto thiol-derivatized molecules as shown in Scheme I. Scheme I shows a schematic diagram of the electrochemical reconstitution procedure using immobilized ferritin electrodes. DTSP is used as a protein cross-linking reagent through acylation of primary or secondary amino groups [30]. DTSP is also adsorbed onto Au surfaces through the disulfide group, so that the terminal succinimidyl groups are available to react with amino-containing biomolecules [31-33]. Immobilization of ferritin on the Au electrode is achieved by the methods based on DTSP and 3-mercaptopropanol (MPOH) mixed selfassembled monolayer (SAM) as shown in Scheme Ib. The DTSP modified electrode was prepared as follows: polycrystalline gold electrode was cleaned with piranha solution and 
immersed in a dioxane with $1 \mathrm{mM}$ DTSP containing $10 \mathrm{mM} \mathrm{MPOH}$ for $1 \mathrm{hr}$ at room temperature. Then the SAM-modified electrode was thoroughly rinsed with acetone and finally with $25 \mathrm{mM}$ HEPES buffer (pH 7.3). Immediately after preparation, the DTSPmodified electrode was immersed in a solution of $2 \mathrm{mg} / \mathrm{ml}$ ferritin in $50 \mathrm{mM}$ HEPES buffer with $50 \mathrm{mM} \mathrm{NaCl}(\mathrm{pH}$ 7.3). The electrode was immersed in the ferritin solution for $18 \mathrm{hr}$ at $4{ }^{\circ} \mathrm{C}$ and then rinsed with $25 \mathrm{mM}$ HEPES buffer. At this point the ferritin is anchored to the $\mathrm{Au}$ electrode through the SAM as depicted in Scheme Ic. Electrochemical removal of metals from the immobilized ferritin was carried out in $0.05 \mathrm{M}$ phosphate buffer ( $\mathrm{pH} 7.5$ ) solution with a chelating agent of ethylenediaminetetraacetic acid (EDTA) bisodium salt at room temperature. The ferrihydrite metal core inside the ferritin is removed during a potential sweep from 0.5 to $-0.9 \mathrm{~V}$, which is more negative than the reduction potential of Fe(III) with EDTA (see Scheme Id). The reduced Fe(II) is released through the hydrophilic channel in the ferritin protein shell and chelated by EDTA. After removing the metal cores with the chelating agent, the electrode was thoroughly washed with 25 mM HEPES buffer. The immobilized ferritin, without the metal core, was immersed into a solution with the volume ratio of 3 to 1 of $0.05 \mathrm{M}$ HEPES buffer $(0.05 \mathrm{M})$ and $\left(\mathrm{NH}_{4}\right)_{2} \mathrm{PtCl}_{4}(0.05 \mathrm{M})$ for 30 min. The apoferritin containing platinum ion was washed with 0.025 M HEPES buffer several times and inserted into $0.05 \mathrm{M}$ phosphate buffer again. Electrochemical biomineralization of ferritins with Pt ions was accomplished by a potential sweep from 0.2 to $-1.0 \mathrm{~V}$ which is more negative than the potential of $\mathrm{PtCl}_{4}{ }^{2-}$ ion reduction. Platinum ion is electrochemically reduced to platinum through potential cycling (see Scheme Ie). Repetition of this process increases the number of atoms inside the ferritin. The Pt-cored 
ferritin was also fabricated through chemical reduction with $\mathrm{NaBH}_{4}$ on immobilized apoferritin for reference.

\subsection{Thiolation of Ferritins}

The ferritin molecules were immobilized on Au through the modification of the ferritin shell directly with thiol groups. The procedure for ferritin thiolation is based on a method described by Traut et al. [34,35], with proper modifications to introduce free thiol groups on the $\mathrm{Au}$ surface for immobilizing the protein molecule. Triethanolamine hydrochloride buffer solution consists of triethanolamine hydrochloride $(50 \mathrm{mM}), \mathrm{KCl}(50$ $\mathrm{mM})$, and $\mathrm{MgCl}_{2}(1 \mathrm{mM})$. A stock solution consisting of 2-iminothiolane $(0.5 \mathrm{M})$, triethanolamine hydrochloride $(1.0 \mathrm{M})$, and triethanolamine $(1.0 \mathrm{M})$ with a $\mathrm{pH}$ of 8.0 was prepared immediately before use. The reaction mixture was prepared as follows: $77.73 \mu \mathrm{l}$ of horse spleen ferritin (HoSF) $(77 \mathrm{mg} / \mathrm{ml})$ or $85.5 \mu \mathrm{l}$ of apoferritin $(55 \mathrm{mg} / \mathrm{ml}), 200 \mu \mathrm{l}$ of mercaptoethanol, and $24 \mu \mathrm{l}$ of the stock solution were placed in a vial and diluted to $20 \mathrm{ml}$ with triethanolamine hydrochloride buffer. The reaction was then incubated for $20 \mathrm{~min}$ at 0 ${ }^{\circ} \mathrm{C}$. After completion, the reaction was quenched by reducing the $\mathrm{pH}$ to 4 with a diluted $\mathrm{HCl}$

solution. The excess reagent was removed by dialysis against 100 volumes of triethanolamine hydrochloride buffer at $4{ }^{\circ} \mathrm{C}$ for $4 \mathrm{hr}$. The Au electrode was then immersed in the thiolated ferritin solution for more than $18 \mathrm{hrs}$ at room temperature and rinsed with $25 \mathrm{mM}$ HEPES buffer to fabricate an immobilized ferritin SAM. Fabrication of Pt-cored ferritins with as prepared thiolated ferritins is similar to that shown in Scheme I.

\subsection{Electrochemical and Microscopic Measurements}


Cyclic voltammograms (CVs) and linear sweep voltammograms (LSVs) were recorded using an EG\&G PAR 273A potentiostat/galvanostat controlled by Power Suites software. Quartz crystal microbalance (QCM) and electrochemical QCM (EQCM) measurements were performed using QCA 922A (EG\&G) operated by WinEchem software. For QCM/EQCM analysis, Au-plated quartz electrodes $(9 \mathrm{MHz}$ AT-cut) were cleaned with doubly distilled, deionized water followed by immersing in a piranha solution. An increase in mass corresponds to a decrease in frequency according to the Sauerbrey equation [36]:

$$
\Delta m=-C_{f} \cdot \Delta f
$$

where, $\Delta \mathrm{m}$ is the mass change, $\Delta \mathrm{f}$ is the change in frequency, and $\mathrm{C}_{\mathrm{f}}$ is the sensitivity constant (here, $\mathrm{C}_{\mathrm{f}}$ is $1.068 \mathrm{ng} / \mathrm{Hz}$ for our system). Each solution was purged with nitrogen for 10 min before the acquisition of the electrochemical measurements. Au on silicon wafer (Platypus Technologies, $100 \mathrm{~nm}$ gold thickness) electrodes were prepared as working electrodes for the electrochemical biomineralization of ferritin, according to the above immobilization methods. The $\mathrm{Ag} / \mathrm{AgCl}$ (in $3 \mathrm{M} \mathrm{NaCl}$ ) electrode was used as a reference electrode. The counter electrode was a spiral platinum wire. Field emission-scanning electron microscopy (FE-SEM) equipped with energy dispersive spectroscopy (EDS) and scanning transmission electron microscopy (STEM) were carried out on a Hitachi S-5200 on the immobilized ferritin layers and on the electrochemically and chemically reconstituted Pt-cored ferritin. The immobilized ferritin layer was thoroughly rinsed with $25 \mathrm{mM}$ HEPES buffer and doubly distilled, deionized water, dried in a nitrogen atmosphere, and then subjected to microscopic analysis. 


\section{Results and discussion}

\subsection{Immobilization of Ferritins}

Figure 1a and $\mathrm{b}$ show the frequency changes during DTSP and MPOH adsorption on $\mathrm{Au}$ electrode and ferritin immobilization through reaction with succinimidyl groups of DTSP on DTSP and MPOH-modified Au electrode, respectively. The electrode was kept in the $1 \mathrm{mM}$ DTSP solution containing $10 \mathrm{mM} \mathrm{MPOH}$ in dioxane at room temperature. The frequency change during DTSP and MPOH adsorption is $1960 \mathrm{~Hz}$ for over $10000 \mathrm{sec}$. The ratio of DTSP to MPOH concentration is 1 to 10 . Total number of mixed DTSP and MPOH molecule is $1.2 \times 10^{16}$ calculated with the same number of DTSP and MPOH composition after SAM formation. The frequency change for ferritin reaction with succinimidyl groups of DTSP is $1695 \mathrm{~Hz}$ for $1000 \mathrm{sec}$ (Fig. 1b). The calculated surface coverage of ferritins with these numbers is 0.15 considering succinimidyl group dissociation. Figure 1c shows a FE-SEM image of ferritin immobilized on a DTSP and MPOH-modified Au electrode. Immobilized ferritin molecules are well separated from each other on the Au electrode. The MPOH has the same molecular chain length compared to hydrolyzed DTSP after SAM formation. Single molecules of ferritin were isolated with a sphere-like protein shell of 12 $\mathrm{nm}$ in diameter. The immobilized ferritins were mainly located along the Au grain boundaries of high surface energy. Ferritin molecules can be well immobilized through various $\mathrm{Au}$ surface treatments with thiol-derivatized molecules. The ferritin population on the $\mathrm{Au}$ electrode increases with increasing reaction temperature (not shown). Highly concentrated ferritin layers were obtained through the direct modification of ferritin surface

with thiol derivatized molecules. Figures 2 show FE-SEM images of a thiolated 
holoferritin-SAM on Au. The thiolated holoferritin SAM is a highly-packed and welldispersed monolayer of ferritin on the Au electrode. Gold surfaces are considerably covered by the thiolated holoferritins and the size of a single ferritin molecule is about $12 \mathrm{~nm}$ in diameter, which is in good agreement with the literature value for the size of ferritin [5].

\subsection{Electrochemical Site-Specific Reconstitution of Ferritin}

Figure 3a shows a cyclic voltammogram (CV) of DTSP-modified Au electrode in $0.05 \mathrm{M}$ phosphate buffer $(\mathrm{pH} 7.5)$ at a scan rate of $100 \mathrm{mV} / \mathrm{s}$. It shows the background current of $1.53 \mu \mathrm{A} / \mathrm{cm}^{2}$ at the DTSP-modified electrodes. The DTSP-modified Au electrode was prepared by inserting the cleaned Au substrate into dioxane with $5 \mathrm{mM}$ DTSP for $18 \mathrm{hr}$ at room temperature. Disulfides in DTSP undergo dissociative chemisorption onto the $\mathrm{Au}$ surface to make adsorbed thiolates. In the first scan, the desorption peak of DTSP with three carbon chains appears at $-1.0 \mathrm{~V}$. Faradaic reactions were not observed over the potential range of 0.2 to $-0.8 \mathrm{~V}$. Hydrolyzed DTSP is reduced to MPOH with one proton and one electron on the Au electrode. The desorption peak of DTSP disappeared in the second cycle because DTSP molecules were desorbed during the first cycle and the electrode surface was cleaned.

A ferritin-immobilized Au electrode was also prepared following the above procedure (Scheme I). The electrochemical behavior of this electrode is shown in Fig. $3 b$. The electron transfer between the ferritin core metals and the substrate occurred easily on the immobilized ferritin electrode. The reduction of Fe(III) occurred at $-0.65 \mathrm{~V}$ and then the current decreased gradually depending on the number of cycles but the oxidation of $\mathrm{Fe}(\mathrm{II})$ was not observed in the reverse potential scan. The CVs are consistent with the fact 
that although $\mathrm{Fe}(\mathrm{II})$ is soluble in phosphate buffer, $\mathrm{Fe}(\mathrm{III})$ is not. The rapid oxidation of $\mathrm{Fe}(\mathrm{II})$ to $\mathrm{Fe}(\mathrm{III})$ occurs at $\mathrm{pH} 7$ forming a white precipitate of $\mathrm{FePO}_{4}$, since the phosphate anions have a strong affinity for iron oxyhydroxide[37,38]. Thus, the reduced Fe(II) ions are released to the solution as free Fe(II) ions, followed by a reaction with phosphate ions to form the $\mathrm{FePO}_{4}$ precipitate upon oxidation. Therefore, the electro-oxidation of $\mathrm{Fe}$ (II) is not reversible for the reverse scan. A new cathodic peak grew at $-0.4 \mathrm{~V}$ as the cycling repeated shown by the arrows in Fig. $3 b$. This faradaic reaction is likely caused by the reduction of accumulated and/or diffused $\mathrm{FePO}_{4}$ precipitate onto the substrate as observed in reported work previously [39]. Figure 3c shows the frequency changes accompanying the potential cycling recorded at $10 \mathrm{mV} / \mathrm{s}$ in $0.05 \mathrm{M}$ phosphate buffer $(\mathrm{pH} 7.5)$ to measure the number of Fe atoms released outside the ferritin protein shell. The resonance frequency of ferritin-immobilized QCM electrode increases during each cycle due to the release of reduced $\mathrm{Fe}(\mathrm{II})$ into the buffer solution. The Fe(II) release starts at the reverse potential scan except during the fist scan. It indicates the rate of iron release from inside the ferritin is a slow process due to the passing of the $\mathrm{Fe}(\mathrm{II})$ through the protein shell. The frequency changes recorded during each cycle on the immobilized ferritin electrode were $+265,+139$, $+100,+119$, and $+67 \mathrm{~Hz}$, respectively, for the Fe(II) release. This behavior is consistent with the CV results (see Fig. 3b) showing reduced cathodic current density depending on cycles, indicating that the reduced Fe(II) is released into the solution as had been reported previously [29]. During the forward scan, the slight decrease of frequency is due to proton insertion and precipitation of $\mathrm{FePO}_{4}$ made by combining reduced $\mathrm{Fe}(\mathrm{II})$ and phosphate ions on the electrode surface. It shows that the first reduction process of $\mathrm{Fe}(\mathrm{III})$ is via proton insertion into the $\mathrm{FeOOH}$ matrix to form $\mathrm{Fe}(\mathrm{OH})_{2}$, followed by the dissolution to free $\mathrm{Fe}(\mathrm{II})$ 
ion, which is then released outside the ferritin protein shell. The measured number of ferritins immobilized on DTSP and MPOH-modified Au electrode is $6.59 \times 10^{12}$ from the QCA data (Fig. 1b). Based on the number of ferritins on the Au electrode, the total number of Fe atoms released from one ferritin is approximately 1200 , indicating that the ferritin is releasing around $57 \%$ of the $\mathrm{Fe}$ atoms based on the average number of iron atoms in the HoSF core during the first five cycles [38].

Immobilized ferritin on a DTSP and MPOH-modified Au electrode was inserted into $0.05 \mathrm{M}$ phosphate buffer containing $0.01 \mathrm{M}$ EDTA and then electrochemically cycled to remove the iron cores inside ferritin (see Fig. 4a). In the first cycle, the reduction peak of $\mathrm{Fe}(\mathrm{III})$ to $\mathrm{Fe}(\mathrm{II})$ appeared at $-0.65 \mathrm{~V}$, the same result with EDTA absent. In the second cycle, the reduction process of $\mathrm{Fe}(\mathrm{III})$ disappeared because the reduced $\mathrm{Fe}(\mathrm{II})$ free ions were released outside the ferritin shell and combined with EDTA, and the faradaic current did not appear at $-0.4 \mathrm{~V}$. During this process, the state of immobilized ferritins was changed from holo- to apoferritin. Pt ions were then added and the Pt ions enterd the apoferritin through ionic channels. After washing with HEPES buffer, platinum ions are reduced in the apoferritin core through a potential sweep from 0.2 to $-1.0 \mathrm{~V}$. The $\mathrm{CV}$ of platinum reconstituted ferritin in $0.05 \mathrm{M}$ phosphate buffer ( $\mathrm{pH} 7.5)$ is shown in Fig. $4 \mathrm{~b}$. New reduction and oxidation peaks were induced from the Pt metal in the phosphate buffer. Two reduction peaks and the corresponding oxidation peaks at a more negative potential than $-0.5 \mathrm{~V}$ are likely due to the phosphate ion reduction and oxidation on the platinum particle in the ferritins. The reduction peaks of platinum oxide and gold oxide occurred at 0.1 and $0.4 \mathrm{~V}$, respectively. 
For a clear understanding of this procedure, we tried the same experiment with an apoferritin immobilized Au electrode. Chemically-prepared apoferritin was immobilized onto the DTSP and MPOH-modified Au electrode. The same procedure was repeated as described in Scheme 1 with a $\left(\mathrm{NH}_{4}\right)_{2} \mathrm{PtCl}_{4}$ solution. The result is shown in Fig. 5. The faradaic reaction on the apoferritin immobilized Au electrode did not occur in the potential region of 0.7 to $-0.6 \mathrm{~V}$. The reduction of the remaining $\mathrm{Fe}(\mathrm{III})$ inside the apoferritin occurs at $-0.7 \mathrm{~V}$ with a small shoulder. A CV of platinum reconstituted ferritin shows similar results as the electrochemical reconstitution of immobilized holo ferritin shown in Fig. 4b. Each peak current induced from Pt increases depending on the number of dipping cycles. On the other hand, the reduction process of gold oxide at $0.4 \mathrm{~V}$ decreased due to the increased amount of platinum inside the ferritin. The frequency changes recorded during insertion of platinum ions into the ferritin were about - $364 \mathrm{~Hz}$ for $3000 \mathrm{sec}$ (see Fig. 5c). Based on the number of apoferritins on Au electrode $\left(5.49 \times 10^{12}\right.$ from QCA data (not shown)), the total number of inserted platinum ions inside a ferritin is around $127 \mathrm{Pt} /$ ferritin due to the large size of $\mathrm{PtCl}_{4}{ }^{2-}$.

Figure $6 \mathrm{a}$ and $\mathrm{b}$ show FE-SEM images of Pt-cored ferritin fabricated by electrochemical site-specific reconstitution of ferritin using mixed SAM-modified and thiolated apoferritin-modified $\mathrm{Au}$ electrodes, respectively. The reconstituted Pt-cored ferritin is well-isolated and dispersed across the entire electrode. The size of Pt-cored ferritin is slightly smaller than Fe-cored ferritin because the ferritin size depends on the number of metal atoms inside the ferritin protein shell. Fig. $6 \mathrm{~b}$ is an FE-SEM image of the thiolated apoferritin after reconstitution with Pt. The small white spots in the image are the Pt-cored ferritins with very small amount of Pt atoms. Naturally existing ferritins have a 
negatively charged surface at $\mathrm{pH} 7.5$ because the isoelectric point of ferritin is around $\mathrm{pH}$ 4.5. Therefore, the platinum ion $\left(\mathrm{PtCl}_{4}{ }^{-}\right)$is repelled from the ferritin surface due to the electrostatic repulsion. Nevertheless, the ferritin molecule might have different pathways and binding sites for anions in the ferritin molecule itself allowing for the Pt reconstitution [18]. The entrance of platinum ions into the ferritin is clearly verified with chemically reduced Pt-cored ferritins (Fig. 7). Only the metal cores inside the ferritin cage can be seen in the STEM image due to the relatively low density of the protein shell. The STEM image shows $\mathrm{Pt}_{200}$-cored ferritins with an average platinum diameter of $1.96 \mathrm{~nm}$ analyzed by SIMAGIS Nanotube ${ }^{\mathrm{TM}}$. Using this method, we can control the number of metal atoms inside the ferritin by controlling the total charge passed and the valence of the target metal, as determined by the electrolyte type, $\mathrm{pH}$, and the engaged potentials. In addition, this procedure allows for an electrochemical biomineralization with various metals along with an easy reconstitution without the constraints imposed by stringent operating conditions of $\mathrm{pH}$, temperature and an anaerobic environment.

\subsection{Electrochemical Behavior of Pt-Cored Ferritin}

The electrocatalytic behavior for oxygen reduction was evaluated with the electrochemically site-specific reconstituted Pt-cored ferritin electrodes. Figure 8 shows LSVs for oxygen reduction at a bulk platinum electrode and reconstituted Pt-cored ferritins immobilized on the Au electrodes through various surface treatments in $0.05 \mathrm{M}$ phosphate buffer $(\mathrm{pH} 7.5)$ saturated with oxygen. In the $10^{\text {th }}$ sweep, oxygen reduction on Pt starts from 0.1 and $0.3 \mathrm{~V}$ on Pt-cored ferritin and bulk Pt, respectively. The reduction peak around $0.4 \mathrm{~V}$ is induced by gold oxide reduction. The current density of gold oxide 
reduction at each electrode depends on the surface coverage of Pt-cored ferritin on the $\mathrm{Au}$ electrode. The thiolated ferritin-immobilized electrode forms the highest populated film among these surface treatments. The rising slope in current is similar at the Pt-cored ferritin electrodes, indicating that the oxygen reduction kinetics is almost identical without regard to the preparation methods. The cathodic currents were limited due to the diffusion process through the protein shell. The cathodic current density at the chemically prepared Pt-cored ferritin electrode for oxygen reduction is the highest among the Pt-cored ferritin electrodes due to the population and number of Pt atoms inside the ferritin. This is in good agreement with the FE-SEM results. Although the Pt-cored ferritin needs an overpotential of $0.2 \mathrm{~V}$ to activate compared with bulk Pt, the peak potentials are similar. It is important to note that the amount of Pt in the Pt-cored ferritin electrode is much smaller than the bulk Pt at the same geometric electrode area. The surface coverage and the number of Pt atoms in the unit area of ferritin-immobilized electrode are much smaller than those of bulk Pt, but the current density of electrochemically prepared Pt-cored ferritin represents only half that of the bulk Pt electrode. Estimation of the amount of Pt on the electrode is around $1.36 \mu \mathrm{g} / \mathrm{cm}^{2}$ with $127 \mathrm{Pt}$ atoms in an electrochemically reconstituted ferritin (Fig. 5c) and roughly 1.78 $\mu \mathrm{g} / \mathrm{cm}^{2}$ with $200 \mathrm{Pt}$ atoms on the chemically prepared Pt-cored ferritins (Fig. 7), respectively. This indicates that the electrocatalytic current of the ferritin-stabilized platinum nanoparticles is enhanced by the large surface areas and particle size phenomena in spite of lower loading rate of catalyst. The results shown here were reproducible even after the electrode was left exposed to air for several days.

\section{Summary}


The ferritin protein has hydrophobic and hydrophilic molecular channels through the protein shell, which makes it possible to remove and insert new inorganic phases. Platinum anion coordinated with chloride ions enters the ferritin interior through these channels. Therefore, we can easily modify the electrode surface using immobilization and electrochemical methods with various metal ion solutions without complicated chemical treatments such as extraction, dialysis, and column treatments for removing the unbound metal ions. In addition, the electrocatalytic reduction of oxygen on the nanostructured platinum nanoparticles stabilized with ferritin biomolecules is enhanced by the large surface areas and particle size effects. This method may open up numerous possibilities for practical applications of immobilized ferritins such as high-density data storage devices, bioelectronic devices, and biosensors.

\section{Acknowledgements}

We thank Dr. K. E. Wise (NIA) for many helpful discussions.

\section{References}

[1] C. Ziegler, W. Göpel, Curr. Opin. Chem. Biol. 2 (1998) 585.

[2] I. Willner, B. Willner, E. Katz, Rev. Molec. Biotechnol. 82 (2002) 325.

[3] I. Willner, E. Katz, Angew. Chem. Int. Ed. 39 (2000) 1180.

[4] I. Willner, B. Willner, Trends Biotechnol. 19 (2001) 222.

[5] P.M. Harrison, P. Arosio, Biochim. Biophys. Acta 1275 (1996) 161.

[6] T. Douglas, in: S. Mann (Ed.), Biomimetic Approaches in Materials Science, VCH Publishers, New York, 1996, p 91-115. 
[7] F.C. Meldrum, B.R. Heywood, S. Mann, Science 257 (1992) 522.

[8] K.K.W. Wong, T. Douglas, S. Gider, D.D. Awschalom, S. Mann, Chem. Mater. 10 (1998) 279.

[9] T. Douglas, V.T. Stark, Inorg. Chem. 39 (2000) 1828.

[10] B. Zhang, J.N. Harb, R.C. Davis, J.-W. Kim, S.-H. Chu, S. Choi, T. Miller, G.D. Watt, Inorg. Chem. 44 (2005) 3738.

[11] J.-W. Kim, S.H. Choi, P.T. Lillehei, S.-H. Chu, G.C. King, G.D. Watt, Chem. Commun. (2005) 4101.

[12] F.C. Meldrum, V.J. Wade, D.L. Nimmo, B.R. Heywood, S. Mann, Nature 349 (1991) 684.

[13] P. Mackle, J.M. Charnock, C.D. Garner, F.C. Meldrum, S. Mann, J. Am. Chem. Soc. 115 (1993) 8471.

[14] F.C. Meldrum, T. Douglas, S. Levi, P. Arosio, S. Mann, J. Inorg. Biochem. 58 (1995) 59.

[15] M. Okuda, K. Iwahori, I. Yamashita, H. Yoshimura, Biotechnol. Bioeng. 84 (2003) 187.

[16] T. Ueno, M. Suzuki, T. Goto, T. Matsumoto, K. Nagayama, Y. Watanabe, Angew. Chem. Int. Ed. 43 (2004) 2527.

[17] K.K.W. Wong, S. Mann, Adv. Mater. 8 (1996) 928.

[18] J. Polanams, A.D. Ray, R.K. Watt, Inorg. Chem. 44 (2005) 3203.

[19] B. Warne, O.I. Kasyutich, E.L. Mayes, J.A.L. Wiggins, K.K.W. Wong, IEEE Trans. Magnet. 36 (2000) 3009. 
[20] E.L.Mayes, A. Bewick, D. Gleeson, J. Hoinville, R. Jones, O.I. Kasyutich, A. Nartowski, B. Warne, J.A.L. Wiggins, K.K.W. Wong, IEEE Trans. Magnet. 39 (2003) 624 .

[21] R.J. Cherry, A.J. Bjornsen, D.C. Zapien, Langmuir 14 (1998) 1971.

[22] K.C. Martin, S.M. Villano, P.R. McCurdy, D.C. Zapien, Langmuir 19 (2003) 5808.

[23] F. Caruso, D. Neil Furlong, P. Kingshott, J. Colloid Interface Sci. 186 (1997) 129.

[24] T. Furumo, H. Sasabe, K.M. Ulmer, Thin Solid Films 180 (1989) 23.

[25] C.A. Johnson, Y. Yuan, A.M. Lenhoff, J. Colloid Interface Sci. 223 (2000) 261.

[26] I. Yamachita, Thin Solid Films 393 (2001) 12.

[27] E. Adachi, K. Nagayama, Langmuir 12 (1996) 1836.

[28] S.-T. Yau, P.G. Vekilov, Nature 406 (2000) 494.

[29] M. Tominaga, A. Ohira, Y. Yamaguchi, M. Kunitake, J. Electroanal. Chem. 566 (2004) 323 .

[30] A.J. Lomant, G. Fairbanks, J. Mol. Biol. 104 (1976) 243.

[31] E. Katz, J. Electroanal. Chem. 291 (1990) 257.

[32] P. Wagner, M. Hegner, P. Kernen, F. Zaugg, G. Semenza, Biophys. J. 70 (1996) 2052.

[33] M. Darder, K. Takada, F. Pariente, E. Lorenzo, H.D. Abrũna, Anal. Chem. 71 (1999) 5530.

[34] R. Jue, J.M. Lambert, L.R. Pierce, R.R. Traut, Biochemistry 17 (1978) 5399.

[35] J.M. Lambert, R. Jue, R.R. Traut, Biochemistry 17 (1978) 5406.

[36] M.D. Ward, in: I. Rubinstein (Ed.), Physical Electrochemistry, Marcel Dekker, New York, 1995. 
[37] Y.G. Cheng, N.D. Chasteen, Biochemistry 30 (1991) 2947.

[38] N.Dennis Chasteen, P.M. Harrison, J. Struct. Biol. 126 (1999) 182.

[39] F. Marken, D. Patel, C.E. Madden, R.C. Millward, S. Fletcher, New J. Chem. 26 (2002) 259 . 


\section{Figure Captions}

Scheme I. Schematic diagram for the electrochemical reconstitution of ferritin on immobilized ferritin electrodes.

Fig. 1. Frequency changes during (a) DTSP and MPOH adsorption on Au electrode and (b) ferritin immobilization on DTSP and MPOH-modified electrode. (c) FE-SEM image of immobilized ferritins on DTSP and MPOH-modified Au electrodes.

Fig. 2. FE-SEM images of the SAM of (a) thiolated ferritins on the Au electrode. (b) Magnified image of thiolated ferritins. The cleaned $\mathrm{Au}$ electrode was inserted into the solution with thiolated ferritin for $18 \mathrm{hr}$ and $24 \mathrm{hr}$ at $4{ }^{\circ} \mathrm{C}$.

Fig. 3. (a) CV of DTSP-modified Au electrode in the $0.05 \mathrm{M}$ phosphate buffer at a scan rate of $100 \mathrm{mV} / \mathrm{s}$. (b) CVs, and (c) EQCM data of immobilized ferritin on DTSP and MPOHmodified Au electrode in $0.05 \mathrm{M}$ phosphate buffer ( $\mathrm{pH} 7.5)$.

Fig. 4. CVs of immobilized ferritin on (a) DTSP and MPOH-modified Au electrode in 0.05 M phosphate buffer ( $\mathrm{pH}$ 7.5) containing with $0.01 \mathrm{M}$ EDTA. (b) CV of platinum reconstituted ferritin in $0.05 \mathrm{M}$ phosphate buffer.

Fig. 5. CV of immobilized apoferritin on DTSP and MPOH-modified Au electrode in 0.05 $\mathrm{M}$ phosphate buffer ( $\mathrm{pH}$ 7.5). (b) $\mathrm{CVs}$ of platinum reconstituted ferritin in $0.05 \mathrm{M}$ 
phosphate buffer for first and second dipping processes. (c) Frequency decrease upon addition of platinum ions such that its final volume ratio of HEPES buffer $(0.05 \mathrm{M})$ to platinum ions $(0.05 \mathrm{M})$ is 3 to 1 . The experiment was performed at open circuit potential.

Fig. 6. FE-SEM images of Pt-cored ferritin fabricated by electrochemically site-specific reconstitution using (a) the DTSP- and MPOH-modified and (b) the thiolated apoferritinmodified Au electrodes, respectively.

Fig. 7. STEM image of chemically prepared Pt-cored ferritins. STEM image was taken after addition of $200 \mathrm{PtCl}_{4}{ }^{2-}$ into an apoferritin for 30 min and then reduction with $\mathrm{NaBH}_{4}$ for $10 \mathrm{~min}$.

Fig. 8. LSVs of bulk Pt (line 1) and Pt-cored ferritins (lines 2 (chemically prepared Pt-cored ferritin), 3 (electrochemically reconstituted Pt-cored ferritin), and 4(electrochemically reconstituted Pt-cored thiolated apoferritin)) in $0.05 \mathrm{M}$ phosphate buffer ( $\mathrm{pH}$ 7.5) with saturated oxygen. The scan rate was $100 \mathrm{mV} / \mathrm{s}$. 


\section{Scheme 1.}

(a)

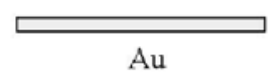

(e)

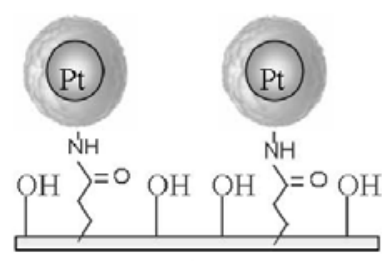

$\mathrm{Au}$

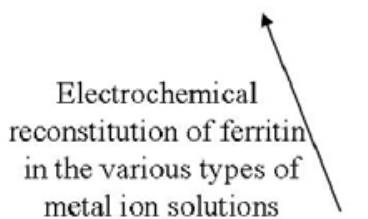

(d)

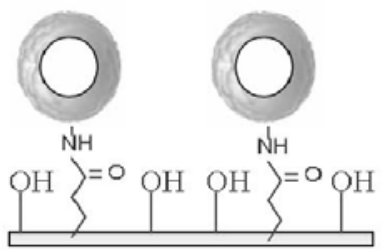

$\mathrm{Au}$ (b)

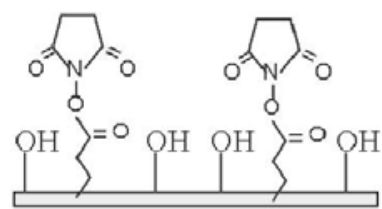

$\mathrm{Au}$

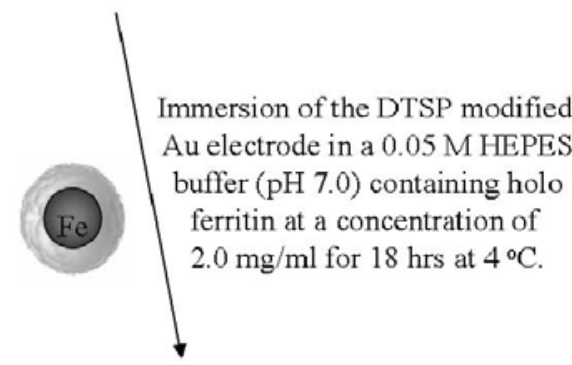

(c)

Electrochemical

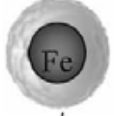

$\mathrm{NH}$

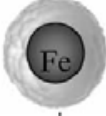

$\mathrm{NH}$

removal of core metal using bpy or EDTA

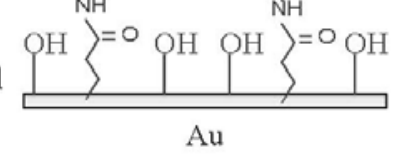


Fig. 1.
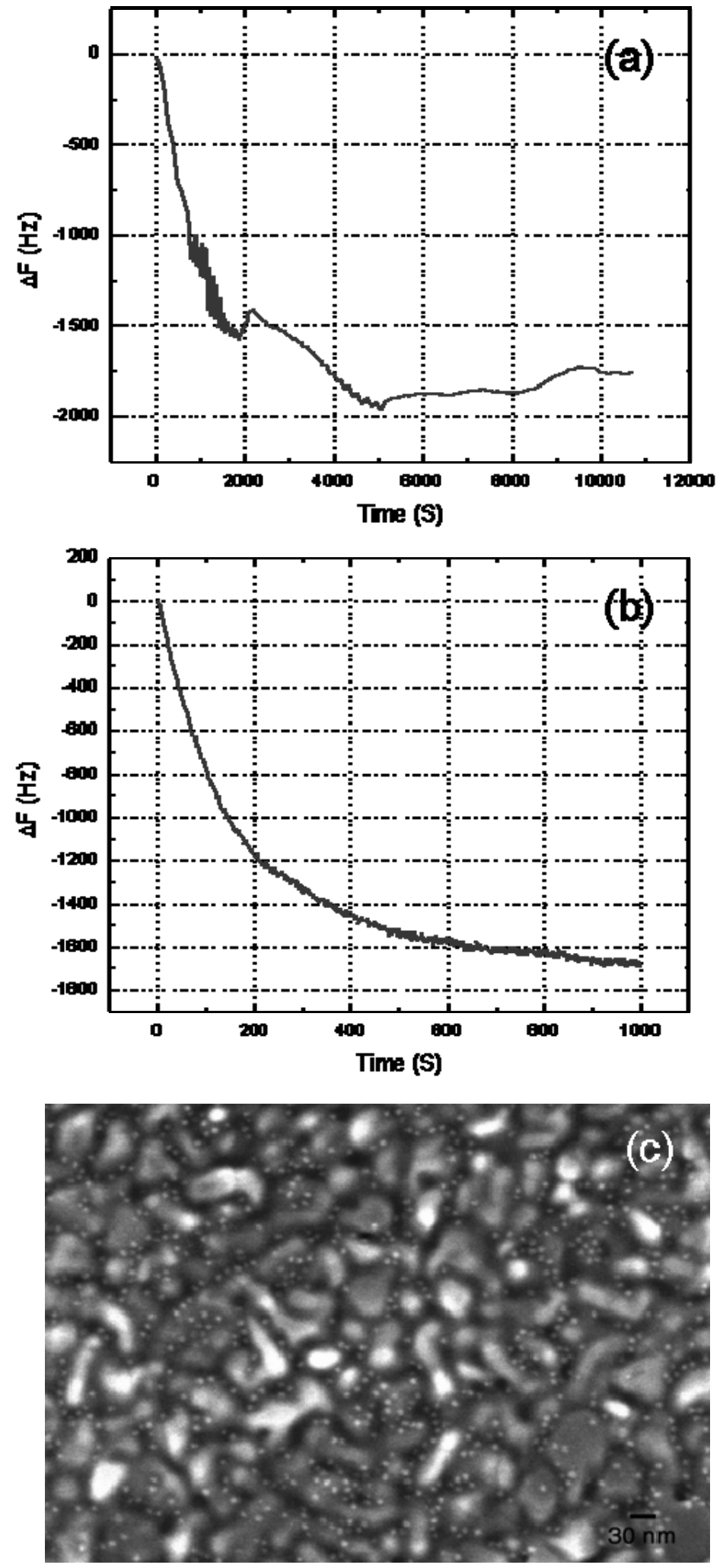
Fig. 2.
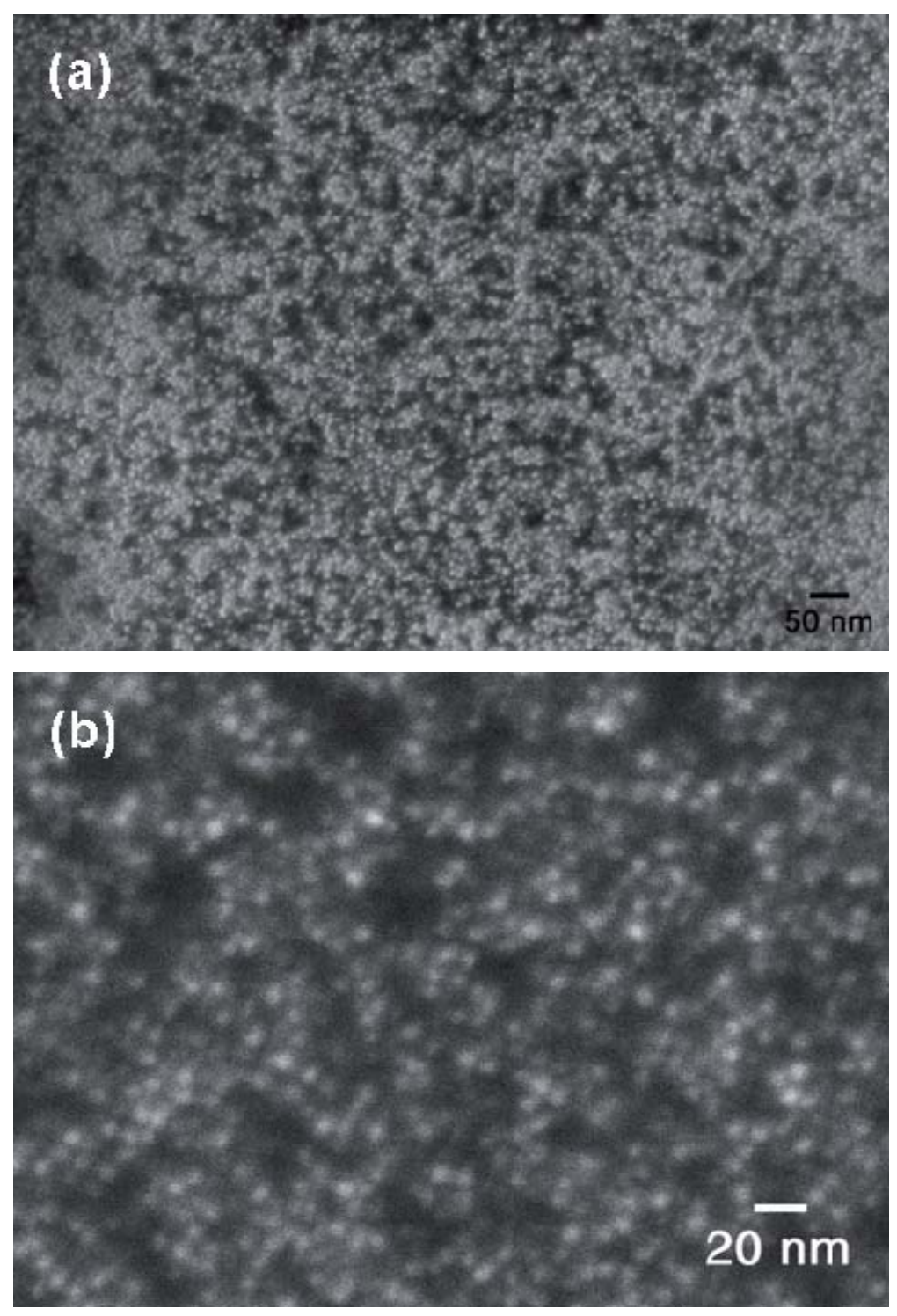
Fig. 3.
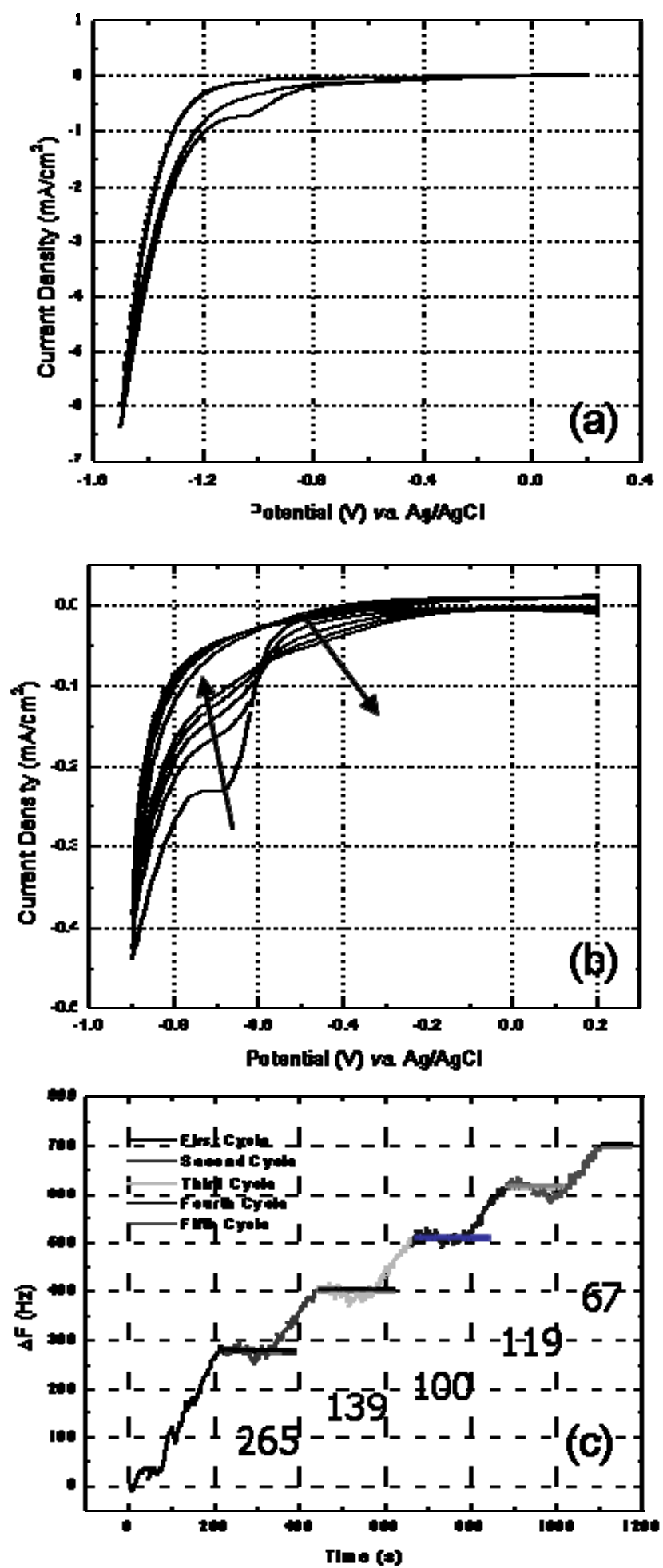
Fig. 4.
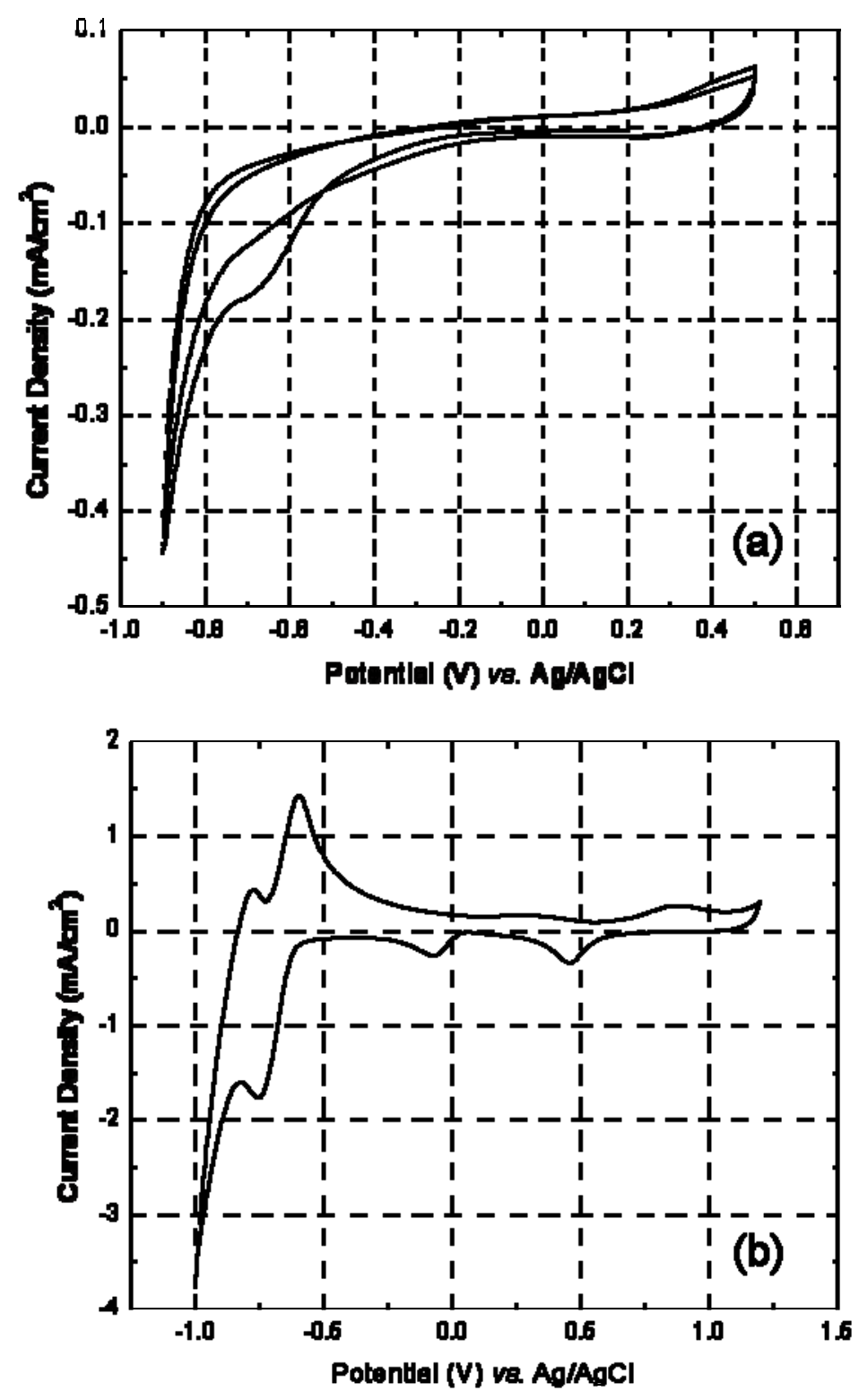
Fig. 5.
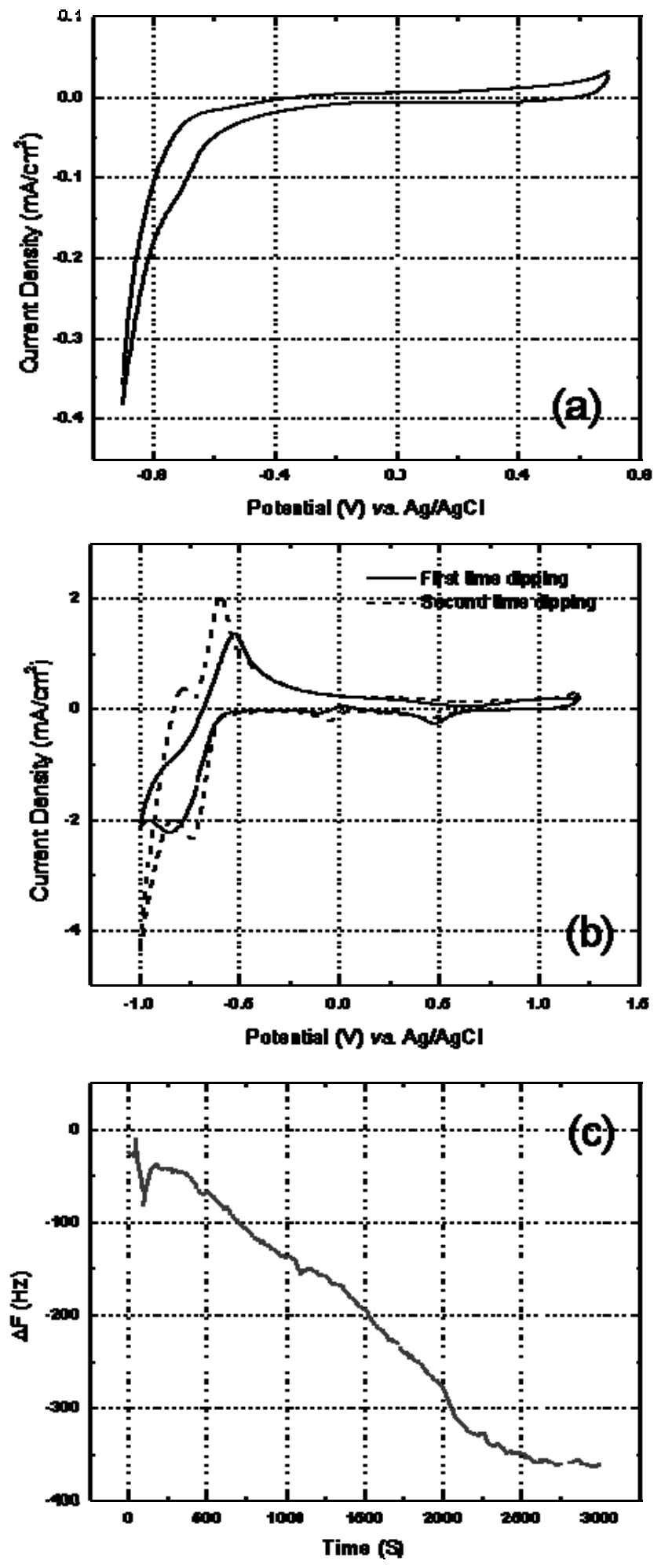
Fig. 6.
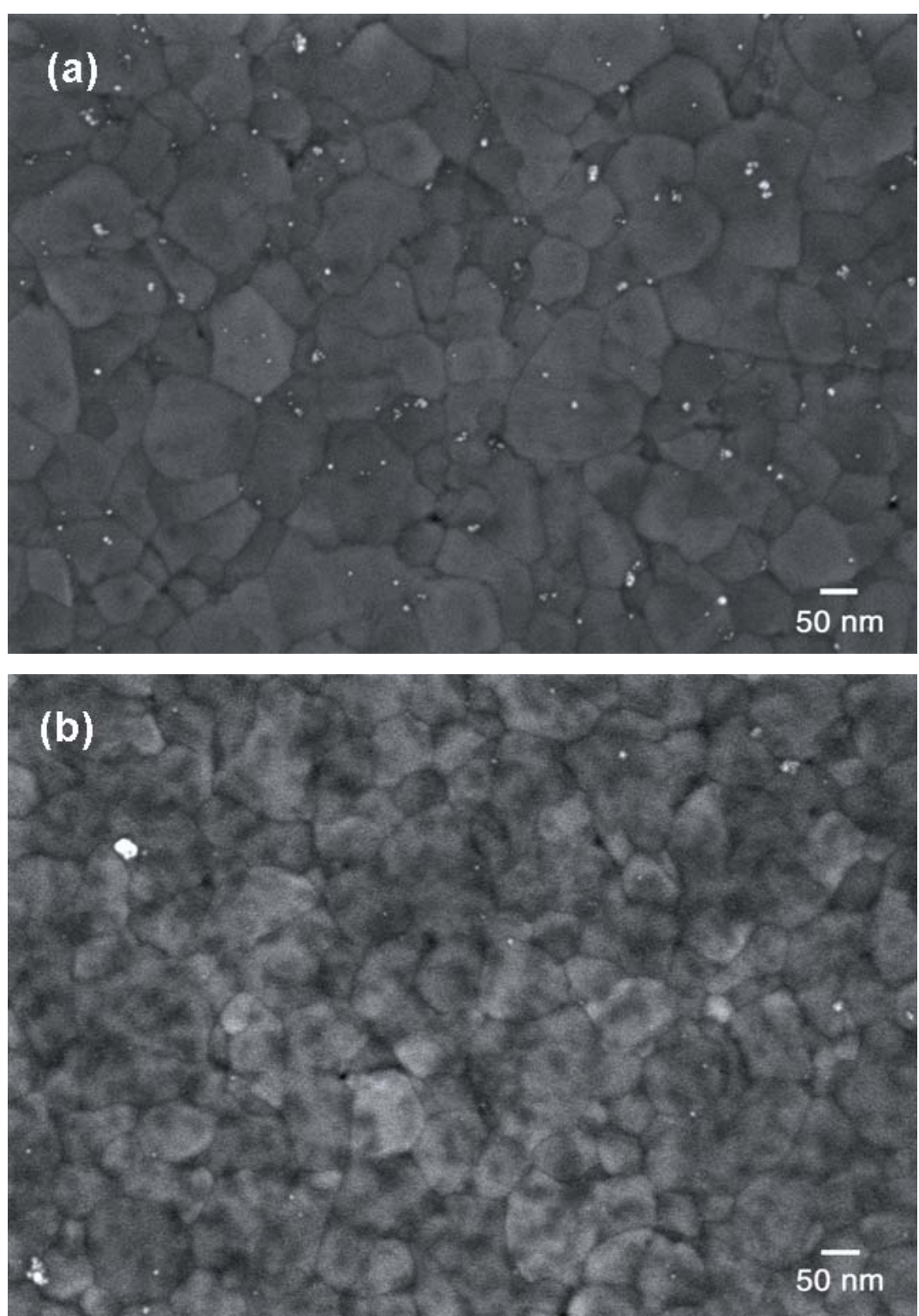
Fig. 7.

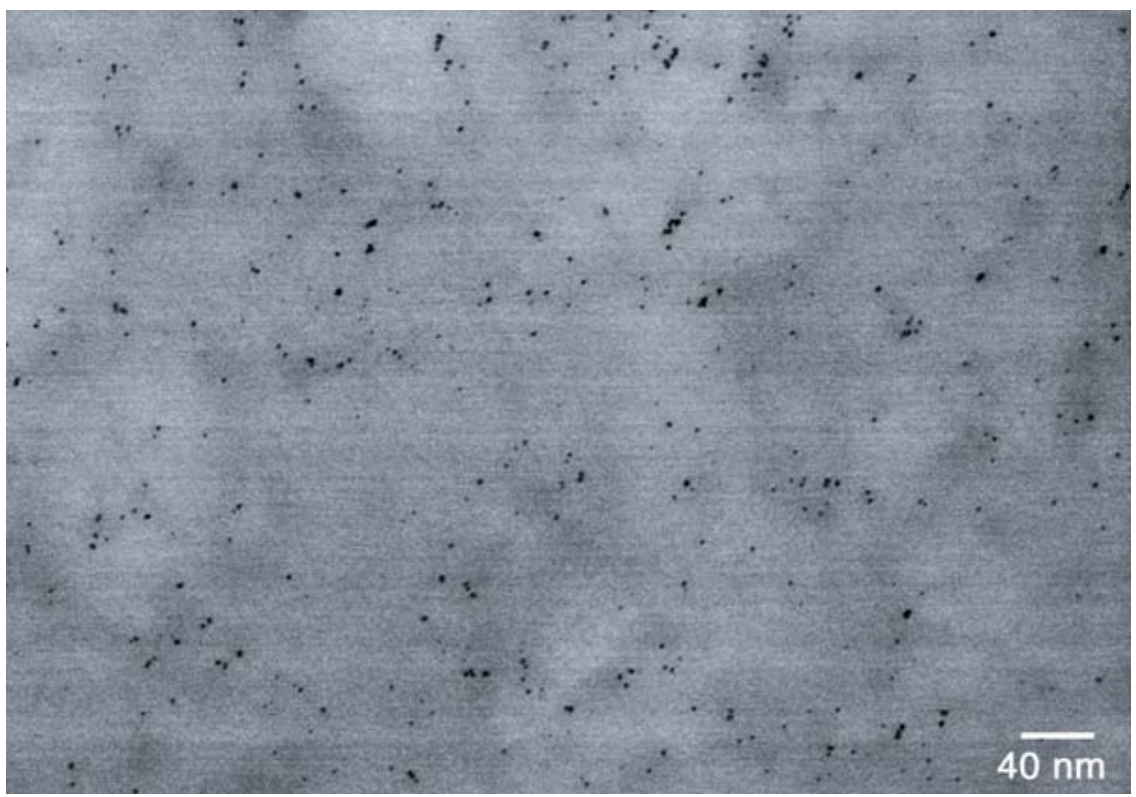


Fig. 8.

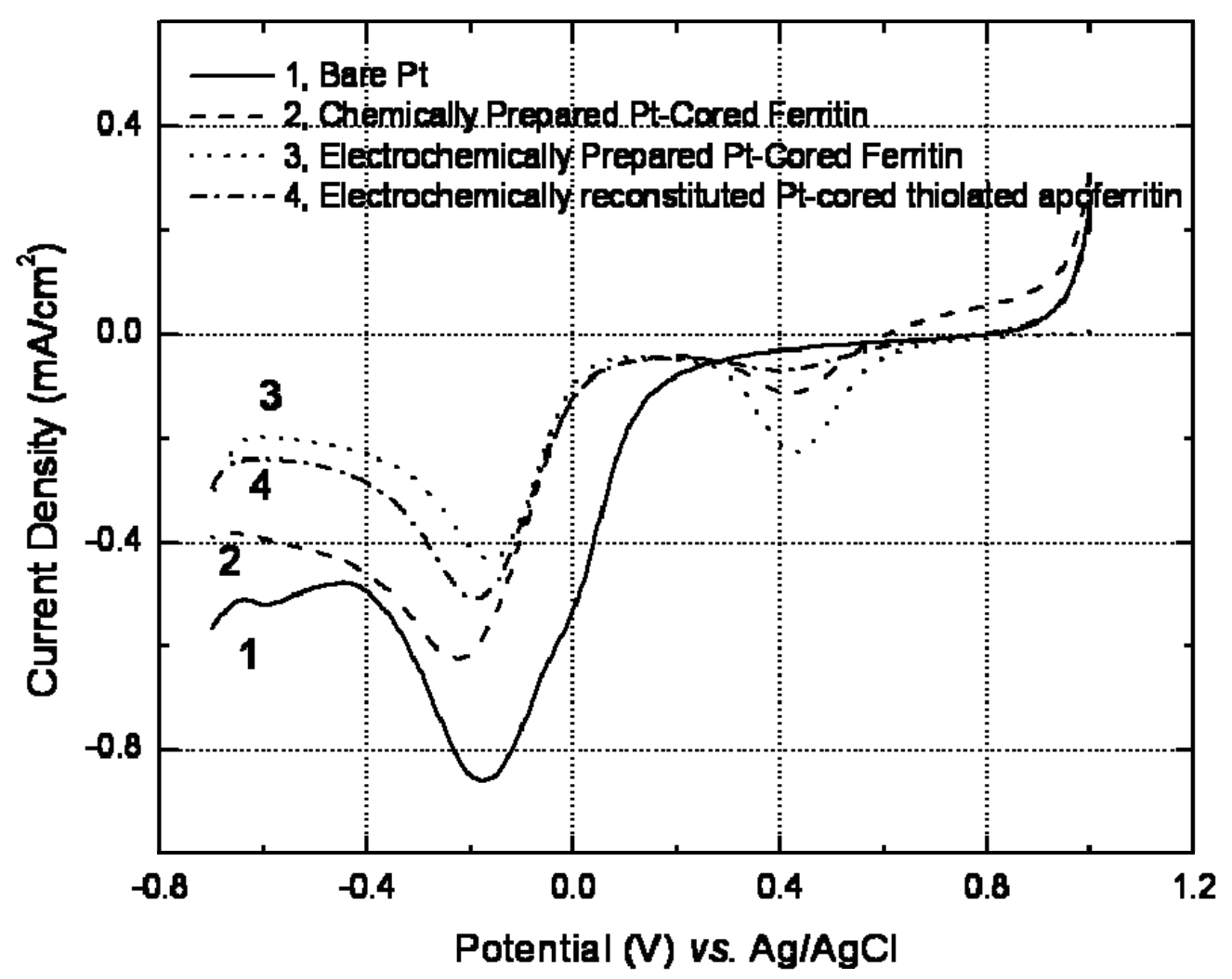

